\title{
Hostel: uma forma de Hospitalidade Aberta
}

\author{
Hostel: An Open Hospitality form
}

\author{
SILVA, Stephanie Ciqueira \\ Universidade Federal do Ceará, Graduada, steephaniesilva@gmail.com
}

MORANO, Raquel Pessoa

Universidade Federal do Ceará, Mestre, raquelmorano20@gmail.com

SANTIAGO, Zilsa Maria Pinto

Universidade Federal do Ceará, Doutora, zilsa@arquitetura.ufc.br

Villarouco, Vilma

Universidade Federal do Ceará, Doutora, vvillarouco@gmail.com

\section{RESUMO}

O mercado do turismo a nível nacional tem, nas últimas décadas, se destacado em sua contribuição ao desenvolvimento social e econômico do país, com o aumento do número de turistas estrangeiros, melhoria da infraestrutura e pelo fato de ter sediado megaeventos, colocando o Brasil no centro das atenções mundiais. Este avanço do setor trouxe a necessidade de expansão e diversificação dos serviços ofertados, criando novos segmentos que se adequem às necessidades de cada público. Surgem novos tipos de turismo como o turismo de aventura, urbano, de megaeventos, ecoturismo. Essa diversificação trouxe também o aumento da criação de meios de hospedagem alternativos. O objetivo deste artigo é fomentar discussões acerca do turismo acessível e de um meio alternativo de hospedagem, o hostel, de custo mais baixo e espacialmente acessível, de forma a possibilitar o turismo a um maior número de pessoas. Para tanto, procurou-se investigar inicialmente a filosofia dos hostels por meio de Revisão de Literatura, de forma a trazer elementos que possam contribuir na produção de espaços de hospedagem acessíveis que se relacionam com o meio em que se insere. Tendo como recorte espacial de estudo, a Praia do Pontal do Maceió em Fortim no Ceará que vem, nos últimos anos, se desenvolvendo economicamente e apresentando um rápido crescimento no número de opções de hospedagem tanto de custos elevados como alternativos.

Arquitetura. Hostel. Turismo. Acessibilidade.

\section{ABSTRACT}

The tourism market at national level has, in recent decades, been highlighted in its contribution to the social and economic development of the country, With the increase in the number of foreign tourists, improvement 


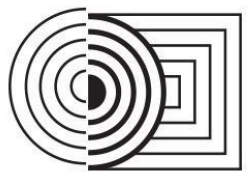

\section{$17^{\circ}$ ERGODESIGN \& USIHC 2019 \\ PUC-Rio, 11 a 13 de dezembro \\ Rio de Janeiro, RJ, Brasil}

$17^{\circ}$ Ergodesign - Congresso Internacional de Ergonomia e Usabilidade

de Interfaces Humano Tecnológica: Produto, Informações Ambientes Construídos e Transporte

$17^{\circ}$ USIHC - Congresso Internacional de Ergonomia e Usabilidade

de Interfaces Humano Computador

of infrastructure and the fact that it has hosted megaevents, placing Brazil in the center of world attention. This advancement of the sector brought about the need to expand and diversify the services offered, Creating new segments that suit the needs of each audience.New types of tourism are emerging, such as adventure tourism, urban, mega-events, ecotourism. This diversification also brought about an increase in the creation of alternative means of lodging. The aim of this article is to foster discussions about affordable tourism and an alternative means of accommodation, the lower cost and spatially accessible hostel, in order to enable tourism to a greater number of people. To this end, we sought to investigate the philosophy of hostels initially through literature review, In order to bring elements that can contribute to the production of accessible lodging spaces that relate to the environment in which it is inserted. Having as spatial cutout of study, Praia do Pontal do Maceió in Fortim in Ceará That comes, in recent years, developing economically and presenting a rapid growth in the number of lodging options both high and alternative costs.

Architecture. Hostel. Turism. Acessbility.

\section{INTRODUÇÃO}

O contínuo crescimento do turismo em todo o mundo, e principalmente no Brasil, conduz a uma necessidade de diversificação e aumento da oferta de serviços aos turistas que chegam, levando a uma segmentação de mercado que possa melhor atender a cada público com suas individualidades. O Plano Nacional do Turismo de 2018-2022 prevê até 2022 resultados de aumento da chegada de estrangeiros de 6,6 milhões para 12 milhões e a ampliação da receita cambial do turismo dos atuais US\$ 6,6 bilhões para US\$ 19 bilhões (MTur, 2018).

Nota-se assim um esforço por parte do governo em inserir o Brasil entre as maiores potências do turismo no mundo, impulsionando assim a economia e aumentando a oferta de empregos. Salientada a importância do turismo para o mundo e para o Brasil (Ver Figura 1), o que se tem notado também nas últimas décadas são fortes mudanças no segmento do turismo, com serviços cada dia mais personalizados. Cada vez mais os turistas buscam por viagens flexíveis e baratas feitas com pequenos grupos. Assim sendo, tipologias alternativas começam a ganhar força, como pode-se verificar no Estudo da Demanda Turística Internacional (2015), que mostra o crescimento do interesse de estrangeiros por campings, albergues e hospedagens de baixo custo, de 1,6\% em 2014 para 5,5\% em 2017.

O hostel surge neste cenário como um tema interessante por ser diferente das tipologias comumente encontradas no Brasil, oferecendo aos hóspedes espaços de convívio, compartilhamento de unidades de hospedagem e preços mais acessíveis. Para além da diversidade de hospedagem, em busca de elevar os debates acerca da acessibilidade universal em equipamentos de turismo, levando em conta a última atualização da ABNT NBR 9050 em 2015, é de fundamental importância verificar seus rebatimentos no âmbito da arquitetura hoteleira.

Não há uma data específica ou um marco inicial que relacione a inclusão de pessoas com deficiência e o turismo. Foram anos de luta para se dar o mínimo a uma classe excluída dos processos de planejamento e decisões que regem a sociedade contemporânea para se ganhar um espaço, que, somente há poucas décadas, foi garantido por direito e não por meios conflitantes. Tem-se notícia que os primeiros estudos sobre as experiências das pessoas com deficiência no turismo se iniciaram em 1998, no estado de Nova Gales do Sul (Austrália). E estes foram usados como estimativas para o governo conhecer o tamanho do mercado e desenvolver as primeiras recomendações para a atividade turística no país, servindo também de base para organização das Olimpíadas e Paraolimpíadas de Sydney no ano 2000 (HONORIO, 2014). 
Figura 1: Mapa do fluxo turístico internacional para o Brasil - 2016

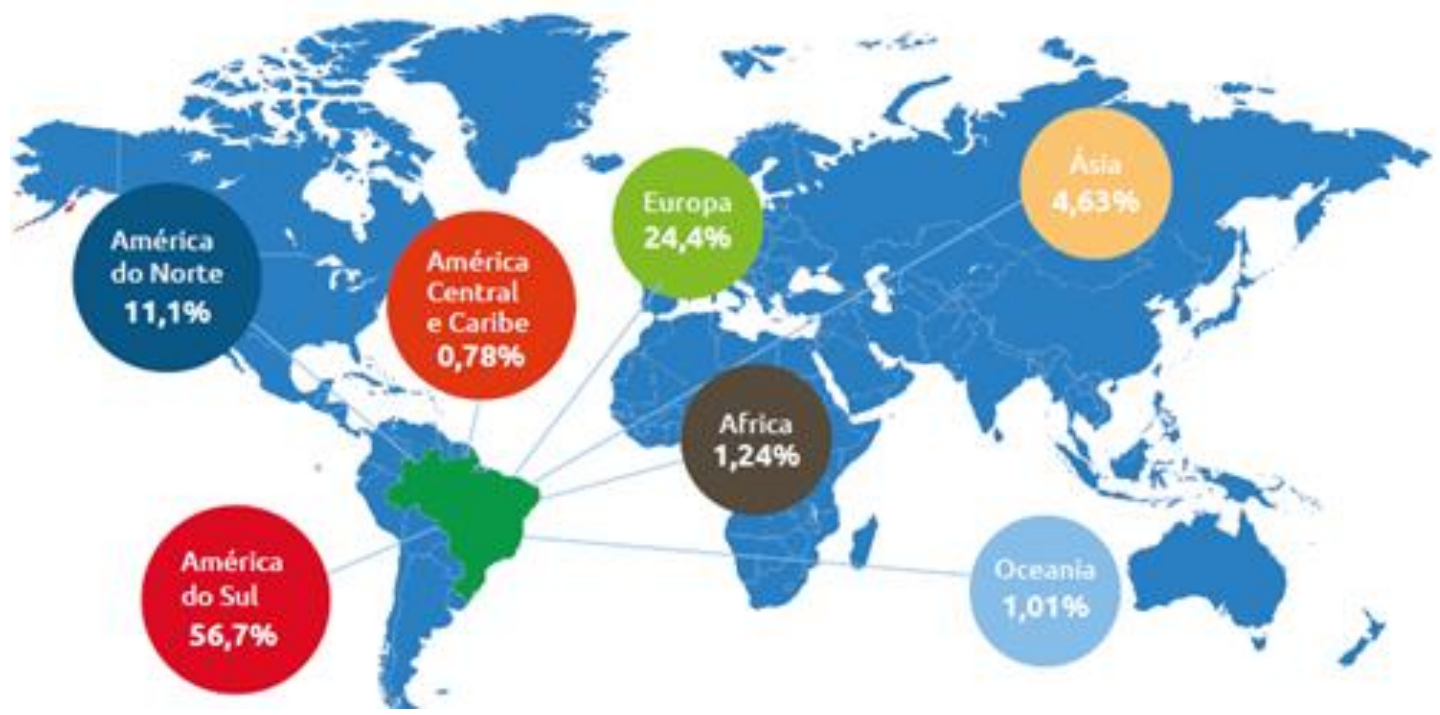

Fonte: MTur, 2017.

Não há uma data específica ou um marco inicial que relacione a inclusão de pessoas com deficiência e o turismo. Foram anos de luta para se dar o mínimo a uma classe excluída dos processos de planejamento e decisões que regem a sociedade contemporânea para se ganhar um espaço - que somente há poucas décadas foi garantido por direito, e não por meios conflitantes. Tem-se notícia que os primeiros estudos sobre as experiências das pessoas com deficiência no turismo iniciaram-se em 1998, no estado de Nova Gales do Sul (Austrália), e foram usados como estimativas para o governo conhecer o tamanho do mercado e desenvolver as primeiras recomendações para a atividade turística no país, servindo também de base para organização das Olimpíadas e Paraolimpíadas de Sydney no ano 2000 (HONORIO, 2014).

Uma questão recorrente no turismo para estes grupos é a falta de condições de acessibilidade condizentes com as suas peculiaridades: meios de transporte inadequados, pacotes turísticos que não atendem às suas necessidades, equipamentos de hospedagem despreparados, ausência de serviços de apoio condizentes com suas características (HONORIO, 2014).

Ao se pensar na formatação dos produtos turísticos, é essencial verificar as condições de acessibilidade, buscando meios para incrementar informações da demanda local, nacional e internacional de pessoas com deficiência. $E$ no que diz respeito às condições de hospitalidade, o espaço deve proporcionar condições para a interação entre as pessoas, independentemente de sua condição física e/ou social. É importante pontuar que a acessibilidade é de responsabilidade do Poder Público, tendo a iniciativa privada parcela de comprometimento com a qualidade no acesso ao turismo ofertado às pessoas com deficiência (CARVALHO; MOREIRA; LIMA, 2009).

Reconhecendo os direitos da pessoa com deficiência e o respeito à diversidade dos usuários de todos os bens e serviços da sociedade, torna-se essencial o debate e a implementação de equipamentos e serviços turísticos acessíveis, de forma a permitir, incentivar e proporcionar a plena participação desse público no turismo, com igual direito de oportunidades. 


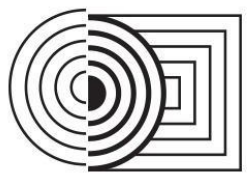

\section{$17^{\circ}$ ERGODESIGN \& USIHC 2019 \\ PUC-Rio, 11 a 13 de dezembro \\ Rio de Janeiro, RJ, Brasil}

$17^{\circ}$ Ergodesign - Congresso Internacional de Ergonomia e Usabilidade de Interfaces Humano Tecnológica: Produto, Informações Ambientes Construídos e Transporte

$17^{\circ}$ USIHC - Congresso Internacional de Ergonomia e Usabilidade

de Interfaces Humano Computador

O objetivo deste artigo é fomentar discussões acerca do turismo acessível e de um meio alternativo de hospedagem, o hostel, de custo mais baixo e espacialmente acessível, de forma a possibilitar o turismo a um maior número de pessoas. Tendo em vista que a motivação para escrita deste artigo foi o trabalho final de Graduação intitulado "Jangada Hostel: uma proposta de hospitalidade aberta" (SILVA, 2019), serão aqui apresentadas algumas propostas deste projeto para que sejam comentadas ao longo do texto, assim, abordaremos possibilidades para situações conflitantes em busca de soluções projetuais acessíveis. Neste sentido, será feita ainda uma análise das condições de meios de hospedagem na Praia de Pontal do Maceió, no Fortim, litoral do Ceará, local onde se desenvolve o projeto já citado, tendo como foco principal a busca pela tipologia hostel como alternativa, diante da oferta hoteleira de alto padrão da região.

\section{METODOLOGIA}

Para a fundamentação teórica, buscou-se leitura de livros e artigos relacionados ao turismo e suas diversas formas, à temática de hotelaria e a albergues da juventude, bem como a pesquisa em fontes de dados oficiais, como o Ministério do Turismo e a Organização Mundial do Turismo (OMT), sobre o turismo no Brasil e no mundo. Analisando as fontes, foi possível constatar um crescimento do turismo no litoral do Ceará, que justifica um possível investimento nesse ramo na região do Pontal do Maceió, área de recorte espacial de estudo.

Além da revisão literária, foram consultadas as recomendações da Hostelling International' e realizado uma visita a um empreendimento da tipologia presente na praia, a fim de entender 0 funcionamento de um hostel e verificar as condições de acessibilidade e a aceitação da tipologia implementada no litoral do Estado.

Para este artigo, são apresentados aspectos relevantes do projeto de um hostel acessível como forma de contribuir para o debate da acessibilidade em edificações destinadas a receber público de turismo social e acessível.

\section{TURISMO E SUAS DIVERSAS FORMAS}

A palavra turismo deriva de tour, que se originou do radical latino tornus, do verbo tornare, que significa girar, voltar, circular. O primeiro conceito relativo ao turismo, refere-se ao ato de viajar, tendo o propósito de deslocamento, com intenção de retorno ao local de partida, local de moradia permanente, portanto, um deslocamento por tempo determinado (Vargas, 2016).

Na pós-modernidade as economias passam a ter na atividade turística uma base significativa, com a cultura também como produto comercializado, gerando todos os anos milhões de empregos diretos e indiretos por todo o mundo. A seguir serão explorados alguns conceitos importantes sobre o turismo para melhor compreensão do fenômeno e do presente trabalho.

\subsection{Turismo sustentável}

A atividade turística, ao mesmo tempo que induz o desenvolvimento regional sustentável, também depende dele, e a sustentabilidade não está apenas na preservação dos recursos

\footnotetext{
${ }^{1}$ A Hostelling International, anteriormente conhecida como International Youth Hostel Federation, é uma associação sem fins lucrativos criada em 1931. É a única rede global de Associações de Albergues da Juventude, contando com cerca de 4.000 estabelecimentos espalhados nos mais de 80 países filiados.
} 


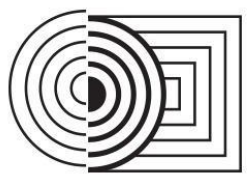

\section{$17^{\circ}$ ERGODESIGN \& USIHC 2019 \\ PUC-Rio, 11 a 13 de dezembro \\ Rio de Janeiro, RJ, Brasil}

naturais, mas também na preservação da cultura e das comunidades em que se insere. No guia "Turismo e Sustentabilidade" do Ministério do Turismo (2016) são apresentados conhecimentos e medidas para tornar os estabelecimentos mais sustentáveis, e o Turismo Sustentável é conceituado: atividade que satisfaz as necessidades dos visitantes e as necessidades socioeconômicas das regiões receptoras, enquanto os aspectos culturais, a integridade dos ambientes naturais e a diversidade biológica são mantidas para o futuro" ( MTur, 2016)

As relações entre turismo e sustentabilidade são trabalhadas em âmbito nacional pelo Ministério do Turismo tomando como base quatro princípios do desenvolvimento sustentável, fundamentais para o Programa de Regionalização do Turismo: sustentabilidade ambiental; sustentabilidade sociocultural; sustentabilidade econômica; sustentabilidade político-institucional (MTur, 2016).

\subsection{Turismo Social}

Conforme a declaração de Montreal (1996), no Congresso do Bureau Internacional de Turismo Social - BITS:

todos os seres humanos têm direito a descansar, a um tempo de ócio, a um limite de horas trabalhadas e a férias pagas"; "o objetivo primário de todas as iniciativas de desenvolvimento turístico deve ser a realização plena das potencialidades de cada indivíduo, como pessoa e como cidadão. (MTur, 2006, s/p)

A principal missão do turismo social é a de incluir, a todos, sem discriminação, promovendo o acesso ao turismo àquelas pessoas que por algum motivo, geralmente financeiro, ou mesmo por limitações física, não podem desfrutar desse tipo de atividade de lazer. O Ministério do Turismo (2006) destaca esse segmento como forma de conduzir e praticar a atividade turística, promovendo a igualdade de oportunidades, a equidade, a solidariedade e o exercício da cidadania na perspectiva da inclusão" (MTur, 2006).

\subsection{Turismo Acessível}

Com relação ao viés acessível do turismo social, já houve uma tentativa do governos nos últimos anos, visando possibilitar a inclusão social e o acesso de pessoas com deficiência ou com mobilidade reduzida à atividade turística, com segurança e autonomia.

Ministério do Turismo criou para o período de 2012 a 2014 o Programa Turismo Acessível, que realizou uma série de estudos que resultaram em cartilhas e guias para melhorar a qualidade dos serviços oferecido ao público com deficiência e mobilidade reduzida, tendo como resultado um conjunto de ações para receber bem a todos e com estrutura permanente implantada na época da Copa do Mundo de 2014 e das Olimpíadas de 2016, sendo os frutos perpetuados depois dos eventos.

Mesmo antes de 2012, já se tinha a produção de cartilhas para esclarecimento de políticas de acessibilidade. De acordo com o Manual de Orientações (Brasil, 2006), para a concessão de Alvará de Funcionamento e da Carta de Habite-se deverá ser observado o cumprimento da acessibilidade previsto respectivamente no $\S 1^{\circ}$ e $\S 2^{\circ}$ do art. 13 do Decreto nํ. 5.296/2004 e nas normas técnicas de acessibilidade da ABNT. 
Conforme o item 4.2.1 do Plano Nacional de Turismo (PNT) 2018-2022, faz parte a iniciativa de melhorar a infraestrutura nos destinos e nas regiões turísticas brasileiras, tendo o Estados e municípios, individualmente ou em parceria com o Governo Federal, o compromisso de apoiar os investimentos de infraestrutura e sinalização turística, para permitir a expansão da atividade e a melhoria da qualidade dos destinos e produtos das regiões turísticas brasileiras, com base nos princípios da sustentabilidade, garantindo acessibilidade às pessoas com deficiência e mobilidade reduzida. (PNT, 2018).

Neste sentido, a forma alternativa de hospedagem - hostel, se alinha com esta perspectiva social do turismo, podendo contemplar também o turismo acessível, embora, ainda não encontre espaço na categorização de hotelaria como veremos a seguir.

\section{HOTELARIA}

O Ministério do Turismo possui o Sistema Brasileiro de Classificação dos Meios de Hospedagem (SBClass), que tem por objetivo organizar o setor hoteleiro e estabelecer um padrão nos serviços de hospedagem. De acordo com o SBClass, os meios de hospedagem variam de 1 a 5 estrelas e são classificados em: hotel, resort, hotel fazenda, cama e café, hotel histórico, pousada, flat/apart hotel.

Como se pode notar, embora os albergues ou hostels sejam levados em consideração nas pesquisas, eles não entram na classificação oficial do MTUr. Sem uma regularização dos órgãos competentes a difusão da tipologia se torna mais complicada, por não haver um padrão de qualidade nem de regras de funcionamento.

\subsection{Origem dos hostels e a Hostelling International}

O conceito de hostel surgiu na Alemanha, com o professor Richard Schirmann, um pouco antes da Primeira Guerra Mundial. No Brasil, a ideia do albergue foi trazida e difundida em 1961, pelo casal de professores cariocas Joaquim e Yone, que conheceram a tipologia na França em 1956 e decidiram ser pioneiros no ramo, instalando a 'Residência Ramos' no bairro de Ramos, no Rio de Janeiro (SILVA, 2019).

O website da Hostelling International define hostel ou albergue como uma acomodação de boa qualidade que oferece uma noite de sono confortável em uma atmosfera amigável e a um preço acessível. Os albergues também oferecem a maneira perfeita de conhecer um país a baixo custo e conhecer muitos viajantes. É interessante ressaltar que (Youth) Hostele Albergue da Juventude têm o mesmo significado e designam a mesma tipologia. A palavra hostel provém de hospitāle e hospice do francês velho e do latim medieval, um lugar para abrigar viajantes, lugar de hospitalidade.

No Brasil, a palavra albergue adquiriu sentido depreciativo, servindo para indicar local de recolhimento para desabrigados, idosos, moradores de rua etc. Isto porque a adoção de albergue vem da época do Império, em que que viajantes, geralmente pobres comerciantes, exploradores e estudiosos, se abrigavam. Possuíam instalações precárias e sua principal função era fornecer comida e local de descanso para os animais desses viajantes, não havendo muita preocupação com o conforto e hospitalidade.

O termo hostel é utilizado em todo o mundo, mesmo os países que não possuem o inglês como 


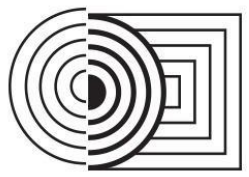

\section{$17^{\circ}$ ERGODESIGN \& USIHC 2019 \\ PUC-Rio, 11 a 13 de dezembro \\ Rio de Janeiro, RJ, Brasil}

$17^{\circ}$ Ergodesign - Congresso Internacional de Ergonomia e Usabilidade de Interfaces Humano Tecnológica: Produto, Informações Ambientes Construídos e Transporte

$17^{\circ}$ USIHC - Congresso Internacional de Ergonomia e Usabilidade de Interfaces Humano Computador

idioma oficial, o usam para definir esse tipo de hospedagem. Portanto, faz mais sentido adotá-lo até mesmo para estar em consonância com o mercado mundial, facilitando a identificação dos turistas estrangeiros.

Um hostel, difere de um hotel ou pousada, pois oferece quartos que têm de quatro a vinte leitos, masculinos, femininos e mistos, mas em uma atmosfera jovem, alegre, gerando no viajante uma sensação de respeito ao próximo, coletividade, possibilitando o convívio com pessoas dentro e fora das unidades de hospedagem. A sala de TV é geralmente o ambiente mais frequentado, onde os hóspedes se reúnem para conversar, ler algum livro disponível no acervo da biblioteca que os hostels geralmente têm. A cozinha se apresenta como outro ambiente bastante utilizado por todos.

Embora não haja regulação específica para hostels no Brasil a EMBRATUR, através da Deliberação Normativa no 433, de 30 de dezembro de 2002, determinou que qualquer empresa que explore ou administre a prestação de serviços de hospedagem em unidades mobiliadas e equipadas e outros serviços a hóspedes, sob qualquer denominação, estará sujeita às normas legais que regem as atividades comerciais ou empresariais, como é o caso do Regulamento Geral dos Meios de Hospedagem, anexo da Deliberativa Normativa no 429 de 23 de abril de 2002. Outro requerimento é cumprir os requisitos básicos da Hostelling International - HI referentes ao atendimento, segurança, limpeza, conforto e privacidade, quando a organização informa via email que é necessário que o hostel tenha (Sandes, 2018): quartos coletivos; quartos para casal/família; cozinha aberta para uso dos hóspedes; sala de convivência; recepção; área de refeições; roupa de cama na diária; empresa constituída legalmente.

No Brasil, e mesmo no Ceará, é bem pequeno o número de hostels associados à rede. Em 2016 dados do IBGE apontavam a existência de 480 hostels/albergues da juventude em todo o Brasil, 17 no Ceará, revelando assim que a grande maioria dos albergues são independentes. O lado negativo dessa situação é a falta de uniformidade no serviço oferecido, uma vez que, ao contrário do que ocorre no exterior, em que os hostels já são bem difundidos.

\section{TURISMO NO LITORAL LESTE DO CEARÁ - APROXIMAÇÃO DA ÁREA DE ESTUDO}

No Ceará, o turismo é uma das atividades mais relevantes desde 1980, quando no governo de Tasso Jereissati - "governo das mudanças", foram feitas mudanças significativas por meio da implementação de políticas públicas que visavam alavancá-lo. Essas iniciativas ajudaram a construir uma nova imagem do Ceará, associando-a às belezas naturais e deixando para trás a ideia de sertão/seca. Para isso, o governo implantou o Prodetur, programa que possibilitou a construção de novas rodovias, duplicou e pavimentou as que já existiam e investiu em aeroportos, tudo para encurtar as distâncias e facilitar o acesso ao litoral. Posteriormente, o Ceará também recebeu investimentos do PAC e do Prodetur Nacional, que permitiram a ampliação do aeroporto Pinto Martins e contribuíram para diversificar e interiorizar o turismo no Estado, deixando-o mais competitivo.

Esses investimentos nas estradas encurtaram as distâncias entre a capital Fortaleza e o litoral, mas uma das ações mais significativas dos programas foi a criação do aeroporto Dragão do Mar, em Aracati, um novo portão de entrada para turistas nacionais e internacionais, fundamental para impulsionar o turismo do litoral leste. Nesse contexto, a 'costa do sol nascente', em que está situado o projeto aqui desenvolvido, acabou se consolidando como uma das áreas mais dinâmicas da costa litorânea do estado. 


\subsection{O Pontal do Maceió}

A Praia de Pontal do Maceió se apresenta como estudo de caso deste trabalho justificado por dois fatores: primeiro pelo fato de estar em desenvolvimento acelerado nas últimas décadas como receptor de turistas nacionais e internacionais (Ver Fig. 2) e, segundo, por estar apresentando novas formas alternativas de hospedagem, o hostel, objeto de interesse de estudo, à medida que sendo hospedagem alternativa, pode vir a se considerar também como turismo social e inclusivo.

Localizado a $150 \mathrm{~km}$ da capital Fortaleza, o distrito Maceió faz parte do município de Fortim, que conta com a proximidade do novo Aeroporto Regional de Canoa Quebrada Dragão do Mar, situado no município vizinho, de Aracati. A Praia do Pontal de Maceió foi muito tempo uma praia desconhecida pela maioria dos turistas, ela tem tomado fama nos últimos anos, após ter sido descoberta pelo francês Jean Michel Chaufour, que encontrou o Pontal do Maceió, uma vila de pescadores com uma beleza única e intocada. Logo, os visitantes que recebia começaram a sugerir que ampliasse o local para receber outros franceses e visitantes do Brasil e do mundo. Foi quando Jean decidiu propor ao filho Célian a ideia de abrir um hotel no lugar, e assim o fizeram. Compraram uma casa à beira mar e transformaram em um hotel, o Vila Selvagem Hotel Contemporâneo, que atualmente conta com 28 bangalôs e ainda se encontra em fase de expansão (SILVA, 2018).

Figura2: Opções de hospedagem no Pontal de Maceió - Fortim - CEI - 2019

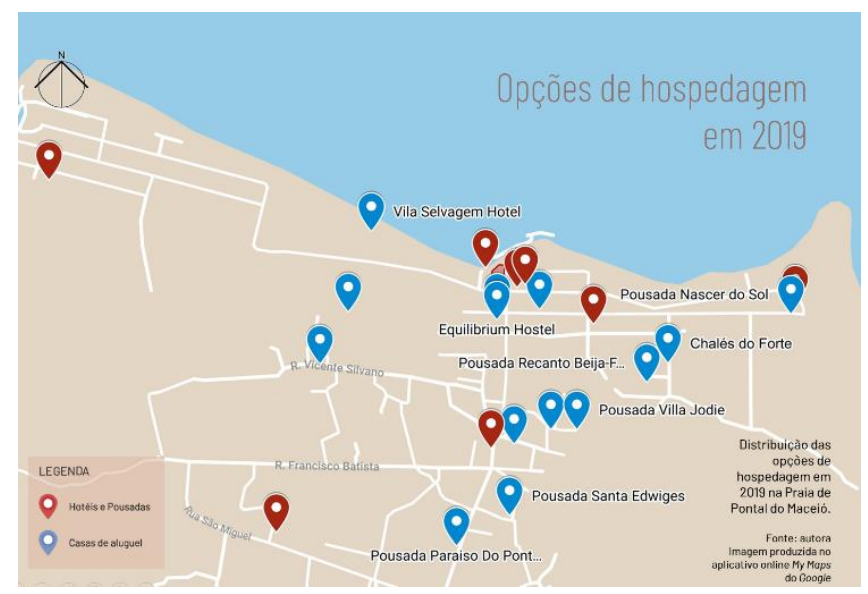

Fonte: Silva, 2019

O crescimento do Pontal do Maceió trouxe um aumento significativo no número de opções de hospedagem disponíveis, mas o que se nota é uma tendência de acomodações de luxo, principalmente mais próximo à praia, com valores consideravelmente altos.

Nesta pesquisa, em busca de hospedagem alternativa na Praia do Pontal de Maceió, verificouse a existência do Equilibrium Hostel. Inaugurado em novembro de 2017, o Equilibrium Hostel é chefiado pelo casal Jorge e Perina Canário. O Hostel conta com duas suítes privativas, que têm uma cama de casal e uma de solteiro, dois quartos compartilhados, um feminino e outro masculino e um misto. Excetuando-se o quarto misto, que apresenta banheiro externo, os demais são suítes. As áreas comuns são compostas por sala de estar com TV, videogame e biblioteca, tudo no mesmo ambiente em que se encontra a recepção, e um terraço superior coberto, com 
mesas de jogos, como sinuca, mesas e bancos, área de convivência. Conta ainda com uma cozinha aberta, utilizada pelo hostel e pelos hóspedes, próximo à uma área aberta, destinada a refeição.

Figura 3: Esquema da planta do Equilibrium Hostel.
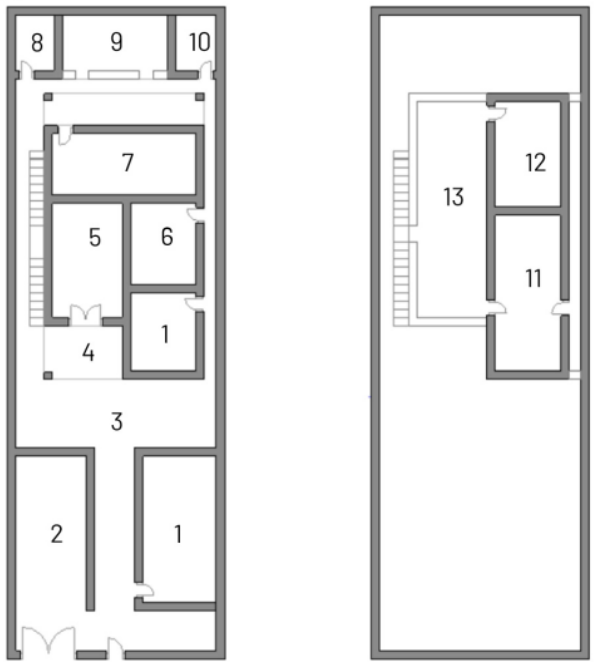

1. Quarto Casal - 2. Garagem - 3. Pátio - 4. Varanda - 5. Recepção/ Estar - 6. Quarto Coletivo Masculino 7. Refeições - 8. Lavanderia - 9. Cozinha - 10. Banheiro - 11. Apto. Hostess - 12. Quarto Coletivo Feminino - 13. Salão de jogos

$$
\text { Fonte: Silva, } 2019 .
$$

Figura 3 e 4: Espaço coletivo e dormitório coletivo do Equilibrium Hostel.

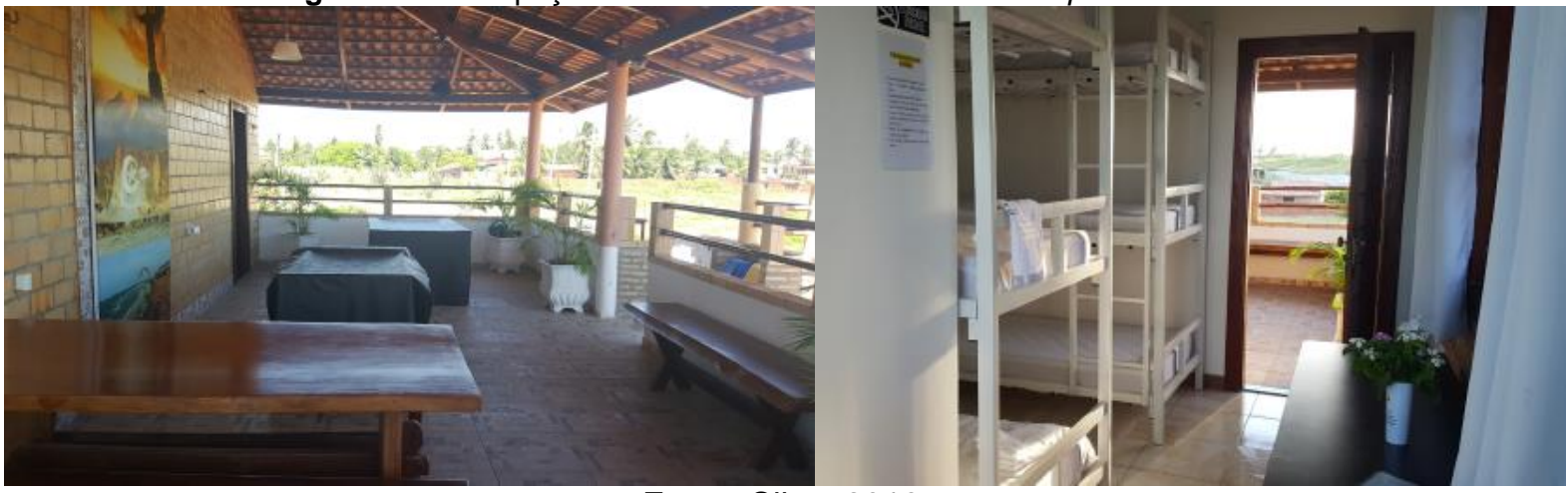

Fonte: Silva, 2019.

Pela visita aos ambientes, verificou-se que as condições de acessibilidade se restringem às áreas comuns de convivência e acesso ao térreo. O que não caracteriza denominar este hostel como acessível, mas visitável. Neste sentido, o hostel existente no Pontal de Maceió não atende satisfatoriamente às condições de acessibilidade constantes no Plano Nacional de Turismo 20182020.

\section{REQUISITOS PARA UM HOSTEL ACESSÍVEL}


Em função de contribuir com o debate sobre hospedagem alternativa inclusiva, apresentaremos alguns aspectos da proposta da Arquiteta Stephanie Ciqueira Silva ${ }^{2}$, que inseriu esta problemática de acessibilidade e turismo social no seu TCC apresentado em junho de 2019 no Curso de Arquitetura e Urbanismo da Universidade Federal do Ceará.

A proposta contempla unidades de hospedagem (UH) tendo como pressuposto a hospedagem acessível e o turismo social. Para o desenvolvimento do projeto primeiro foram seguidas as recomendações e exigências da Hostelling International a fim garantir o padrão de qualidade esperado para tal empreendimento. Tendo a acessibilidade como premissa projetual e, havendo a necessidade da criação de mais de um pavimento com vista a aproveitar o terreno e o visual da praia da melhor forma, um dos principais desafios foi o acesso aos pavimentos, já que um elevador estaria inadequado por conta da maresia e pelo alto custo. A solução foi tomar partido de uma rampa central para unir os dois blocos e com isso propiciar a criação de um grande espaço de convivência central do hostel, tornando-se assim, o coração da edificação.

Fig. 5: Planta de Implantação

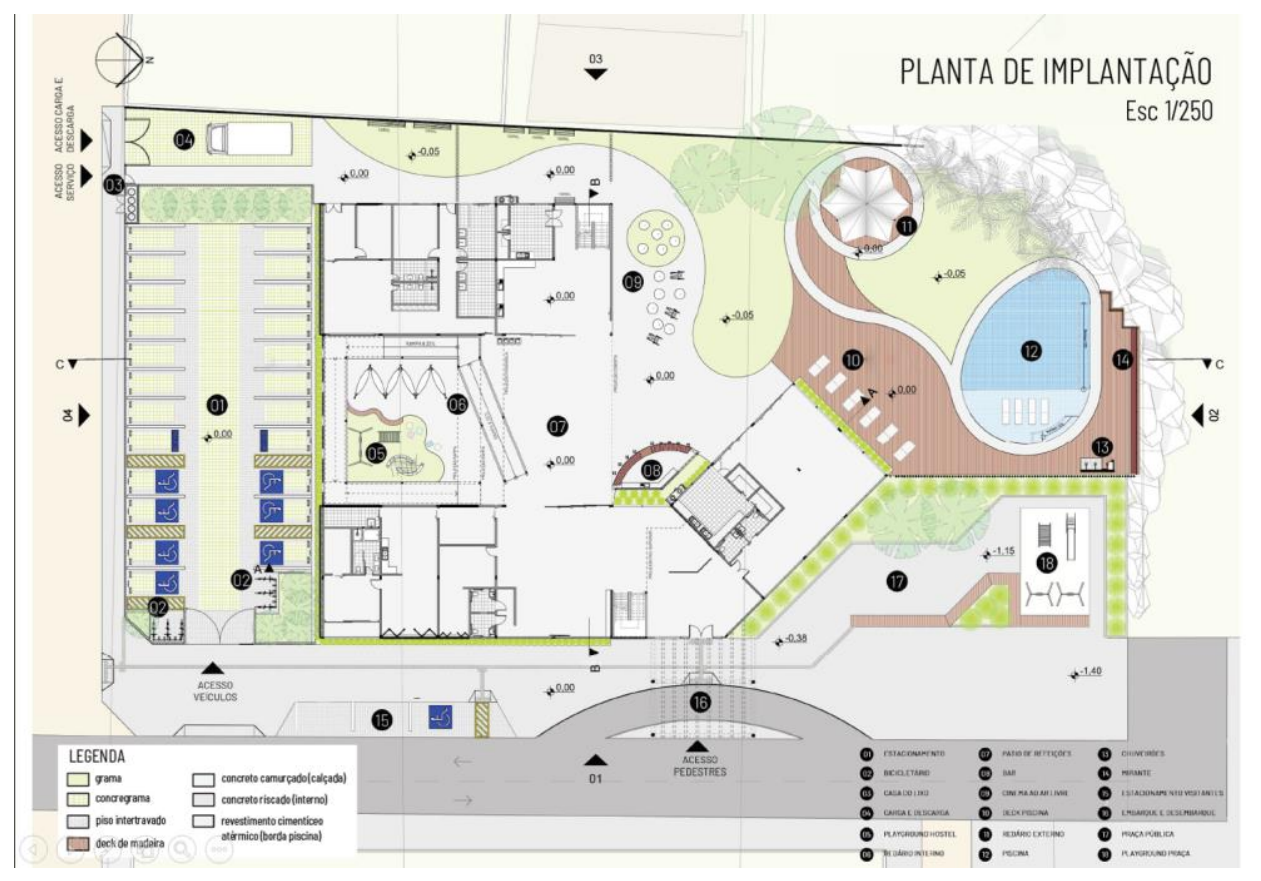

Fonte: Silva, 2019.

Para a condição de modulação adequada a vários tipos de UH e, pensando em facilitar a distribuição da estrutura, foi adotado um módulo baseado nas necessidades da UH. Seu dimensionamento foi concebido de forma a organizar espacialmente o mobiliário, o banheiro acessível e deixar livre um espaço satisfatório para manobras com a cadeira de rodas e, pensado

${ }^{2}$ Participante voluntária da Pesquisa "Acessibilidade arquitetônica $\mathrm{x}$ espaços de hospedagem: Fortaleza está preparada para receber pessoas com deficiência e/ou mobilidade reduzida?", em andamento, mediante aprovação do EDITAL № 7/2019 - PROGRAMA INSTITUCIONAL DE BOLSAS DE INICIAÇÃO CIENTÍFICA - PIBIC 2019-2020 - PIBIC-CNPq | BICT-FUNCAP | PIBIC-UFC | IC-VOLUNTÁRIA 
para que pudesse comportar todas os tipos de UH propostas sem necessitar alteração na modulação. Isto demonstra como as questões espaciais relativas à acessibilidade devem ser pensadas e solucionadas logo na concepção do projeto.

Fig. 6: Módulo da unidade de hospedagem

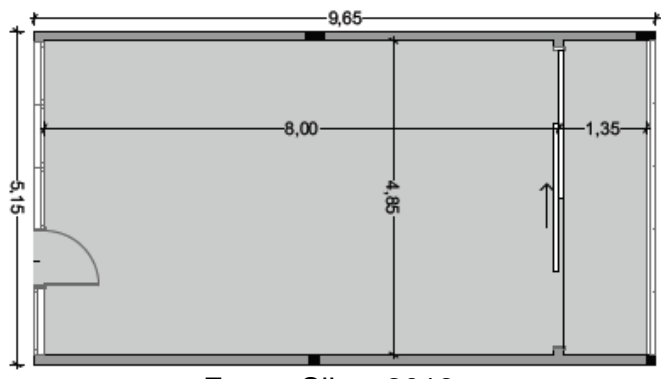

Fonte: Silva, 2018.

O módulo tem 4,85 x 8,00 m na parte interna do quarto e o módulo total de 5,15 x 9,65 m. Este módulo proporcionou espaços internos para arranjos de mobiliário e circulação acessível a todas as tipologias de $\mathrm{UH}$. Com intuito de atender diversos públicos, foram criadas 4 modalidades de $\mathrm{UH}:$ 1. quartos casal; 2. quarto família; 3. quartos quádruplo e 4. quarto óctuplo. Os quartos casal e família são para aqueles que buscam por maior privacidade e podem pagar um valor mais alto.

Fig. 7: Módulo da unidade de hospedagem (quarto casal)

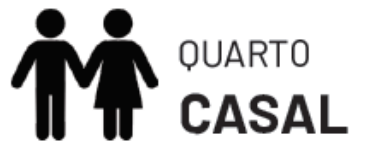

- Banheiro privativo acessível

- Cama king size

- Bancada de apoio

- TV e Frigobar

- Rede tradicional na varanda

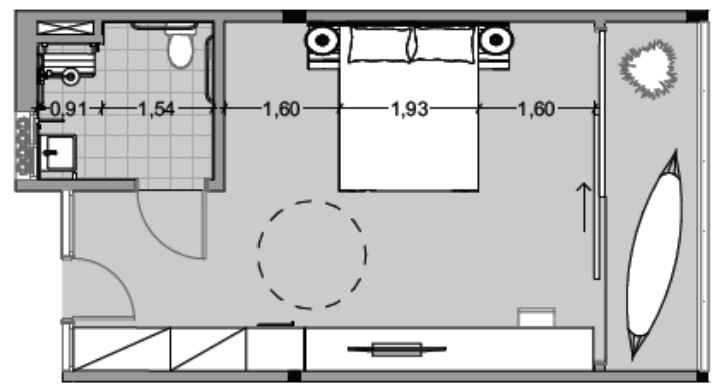

Fonte: Silva, 2019

No quarto família, além da cama de casal foi proposto o beliche acessível (Ver Fig. 8 e 16)

Fig. 8: Módulo da unidade de hospedagem (quarto família)

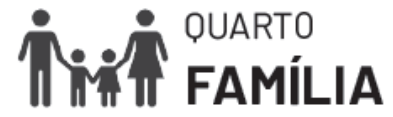

- Banheiro privativo acessível

- Cama queen size

- Beliche acessível

- Bancada de apoio

- TV e Frigobar

- Rede tradicional na varanda

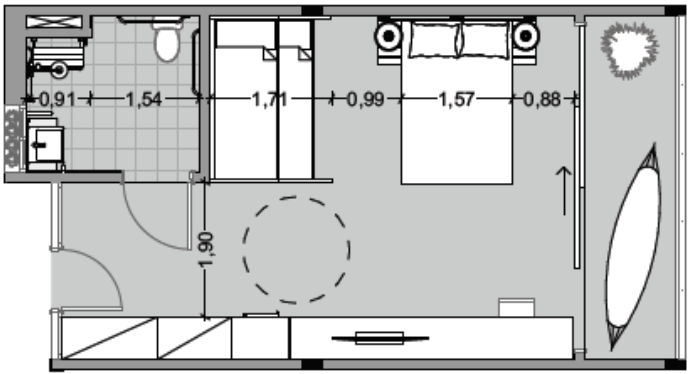

Fonte: Silva, 2019 
O quarto quádruplo pode ser ocupado tanto por pessoas sozinhas quanto ser fechado por um grupo de amigos que queira maior privacidade. Nele são organizados dois beliches, sendo um comum e um acessível. (Ve Fig. 9 e 16).

Fig.9: Módulo da unidade de hospedagem (quarto quádruplo)

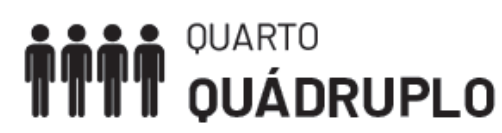

- Banheiro privativo acessível

- Beliche regular

- Beliche acessível

- Bancada de apoio

- TV e Frigobar

- Rede tradicional na varanda

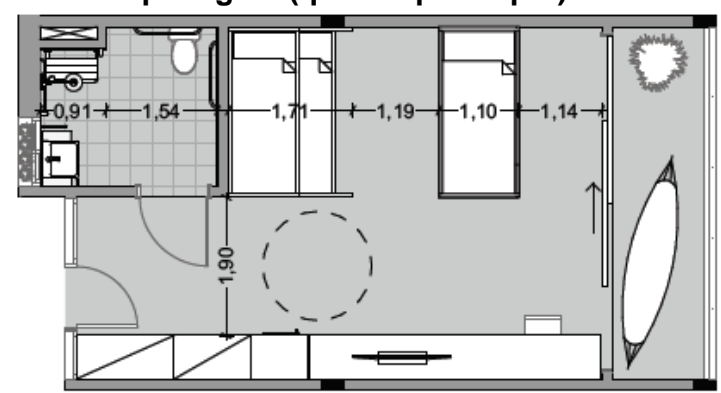

Fonte: Silva, 2019

Finalmente, o quarto óctuplo é voltada tanto para viajantes sozinhos quanto em grupos mas que querem pagar um valor menor e estão dispostos a interagir com pessoas diferentes durante a estadia.

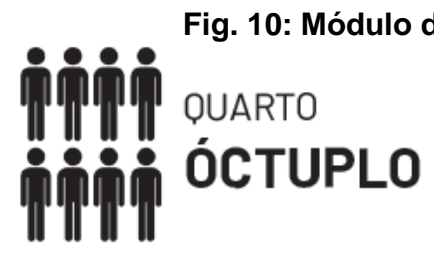

- 4 beliches regulares
- Bancada de apoio
- Mesa com cadeiras
- Armários com tranca
- Rede cadeira na varanda

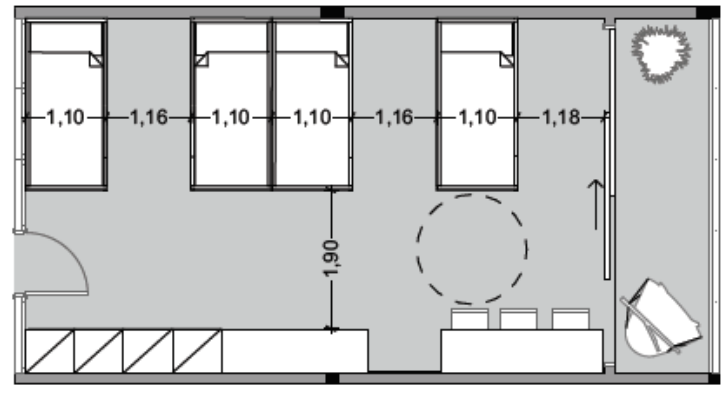

Fonte: Silva, 2019

Para as UH óctuplas foram criados banheiros coletivos no segundo pavimento. Todos os quartos, com exceção dos óctuplos, possuem banheiros internos e acessíveis, com condição de acomodação de usuário em cadeira de rodas, seguindo o que é recomendado pela ABNT NBR 9050/2015 da seguinte maneira:

1. Chuveiro - As barras de transferência da área de chuveiro de um banheiro acessível são de extrema importância, visto que é através delas que o cadeirante consegue sair da cadeira e sentar no banco de banho (barras 4 e 5 da elevação 01) e, no caso de gestantes, idosos ou pessoas com muletas, se levantar do mesmo (barra 3 da elevação 01). O banco de $70 \mathrm{~cm}$ de largura é revestido com madeira naval (resistente à água) e é dobrável para que, caso a pessoa já esteja em uma cadeira de banho, ela consiga entrar embaixo do chuveiro. Ele está a $46 \mathrm{~cm}$ do piso, mesma altura da cadeira de rodas, seguindo assim o princípio 6 do desenho universal, baixo esforço físico: fazer o uso dos equipamentos com menor esforço físico possível. O chuveiro está posicionado distando $70 \mathrm{~cm}$ do banco de banho para que ao sentar a pessoa consiga ter controle sobre que momento entrar embaixo da água, sem risco de afogamento. Seu acionamento é feito por alavanca, 
permitindo que mesmo alguém sem os dedos ou com algum tipo de atrofia nas mãos possa acioná-lo.

2. Lavatório - de semiencaixe, bancada livre a $73 \mathrm{~cm}$ do piso, garantindo a área de aproximação ao cadeirante. A distância da face do lavatório para a torneira é de $50 \mathrm{~cm}$, para que apenas esticando os braços a pessoa na cadeira de rodas consiga acionar a torneira de alavanca (com 23N de força para acionamento, como pede a NBR 9050/2015). A NBR 9050 de 2015 substituiu as barras de apoio vertical), para que assim mais pessoas com diferentes tipos de necessidades possam utilizá-las, como gestantes, idosos e pessoas com muletas. A barra vertical (barra 1 da elevação 01) deve estar a $90 \mathrm{~cm}$ do chão e a barra horizontal (barra 2 da elevação 01) deve distar no máximo $20 \mathrm{~cm}$ da cuba. O espelho, máximo a $90 \mathrm{~cm}$ para que a pessoa consiga se ver de corpo inteiro de frente.

3. Sanitário - A área do sanitário deve contar obrigatoriamente com duas barras horizontais, uma ao fundo do sanitário (barra 1 da elevação 02) e outra na lateral (barra 3 da elevação 02), e uma barra na vertical (barra 2 da elevação 02), permitindo tanto a transferência lateral como a perpendicular com facilidade. A barra do fundo deve estar afastada no mínimo $35 \mathrm{~cm}$ do eixo da bacia sanitária para o lado que o cadeirante se aproxima da mesma, permitindo maior conforto e segurança no momento da transferência. Com a vasta utilização do uso da caixa acoplada a norma de 2015 passou a permitir que a barra do fundo fique a $89 \mathrm{~cm}$ de altura, para facilitar o acionamento do botão da caixa acoplada (o botão de acionamento deve ser alavanca ou botão elevado), enquanto a barra lateral deve estar a $75 \mathrm{~cm}$. A tampa da bacia sanitária também deve estas a $46 \mathrm{~cm}$ de altura, mesma altura da cadeira de rodas, para que com baixo esforço físico a pessoa consiga realizar a transferência.

Fig. 11 e 12: Imagem e Planta Banheiro acessível no projeto Hostel

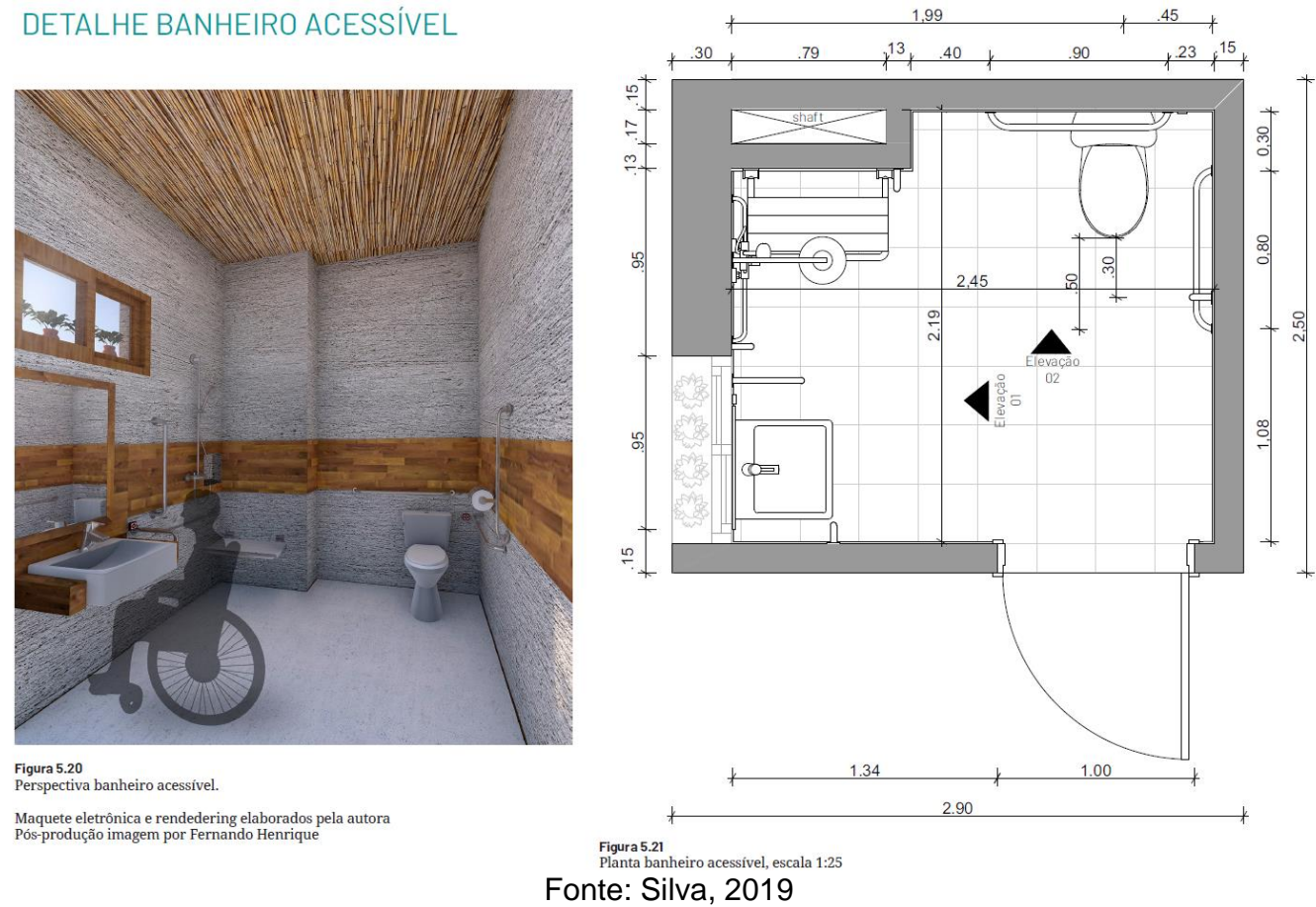


$17^{\circ}$ ERGODESIGN \& USIHC 2019

PUC-Rio, 11 a 13 de dezembro

Rio de Janeiro, RJ, Brasil $17^{\circ}$ Ergodesign - Congresso Internacional de Ergonomia e Usabilidade de Interfaces Humano Tecnológica: Produto, Informações Ambientes Construídos e Transporte

$17^{\circ}$ USIHC - Congresso Internacional de Ergonomia e Usabilidade de Interfaces Humano Computador

Fig. 13 e 14: Vistas Banheiro acessível

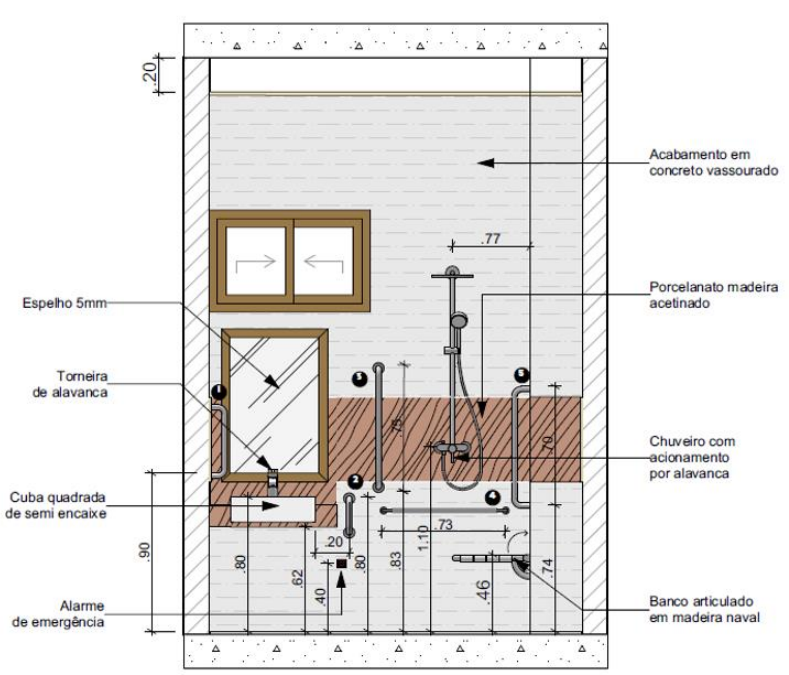

Figura 5.22

Elevação 01, sem escala

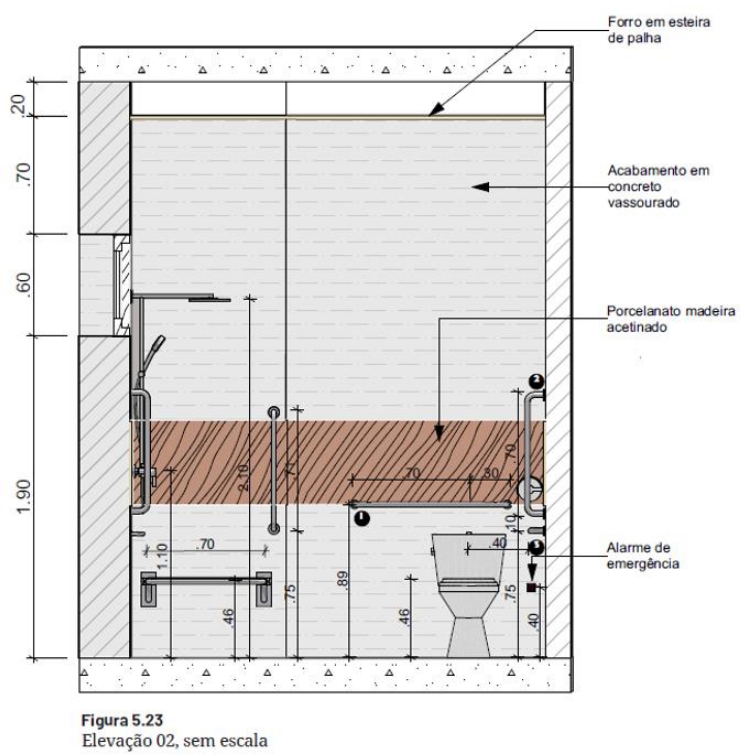

Elevação 02, sem escala

Fonte: Silva, 2019

O chuveiro/ducha da área da piscina também foi concebido seguindo requisitos de acessibilidade (Ver Fig. 15)

Fig. 15: Detalhes Chuveirão

\section{DETALHE CHUVEIRÃO}

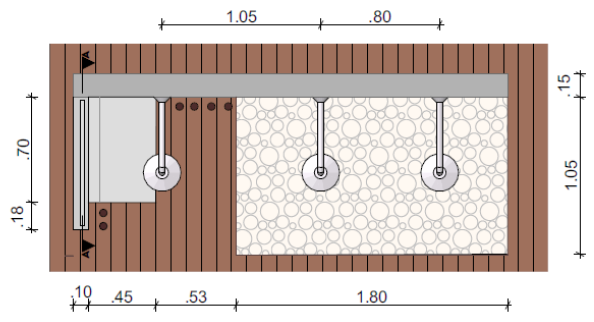

Figura 5.29 Chuveirão em planta.
Fonte: autora

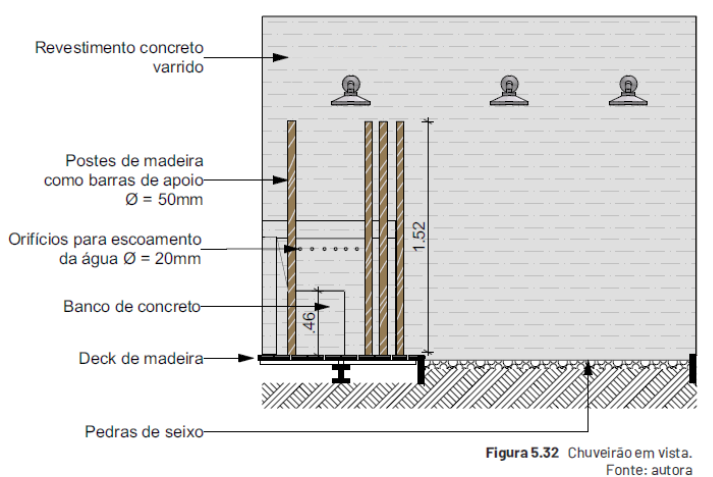

Como a acessibilidade é uma das premissas do projeto, toda a área de lazer foi pensada para que pudesse ser utilizada o mais facilmente por todos. Sendo assim, o projeto conta com uma área de chuveiros com banco de banho que possibilita a utilização por cadeirantes e outras pessoas que necessitem de maior apoio para utilizá-los. As barras laterais tradicionais foram substituídas por postes de madeira e frisos na parede de concreto, permitindo que a pessoa obtenha o apoio necessário.

Fonte: Silva, 2019 


\section{$17^{\circ}$ ERGODESIGN \& USIHC 2019}

PUC-Rio, 11 a 13 de dezembro

Rio de Janeiro, RJ, Brasil $17^{\circ}$ Ergodesign - Congresso Internacional de Ergonomia e Usabilidade de Interfaces Humano Tecnológica: Produto, Informações Ambientes Construídos e Transporte

$17^{\circ}$ USIHC - Congresso Internacional de Ergonomia e Usabilidade de Interfaces Humano Computador

Por se tratar de uma tipologia para atendimento ao público de turismo social e inclusivo, o mobiliário teve que ser pensado de forma mais econômica e ergonômica para atingir os objetivos propostos pelo projeto do hostel.

O mobiliário dos quartos foi feito com $\mathrm{OSB}^{3}$ e pallets ${ }^{4}$, pensando na questão da sustentabilidade. O OSB permite uma grande variedade de usos e aplicações, tendo sido utilizado para as beliches, e para o mobiliário interno como armários e mesas, assim como para móveis das área comuns, algumas vezes com pintura branca em uma das superfícies. Os pallets, foram utilizados para as camas de casal e para os sofás das áreas comuns. Ressalta-se a proposta de beliche com a cama inferior mais larga que a superior para melhor acomodar pessoa obesa ou cadeirante. (Ver Fig. 16 - Beliche acessível)

Fig. 16: Mobiliário com OSB e pallets
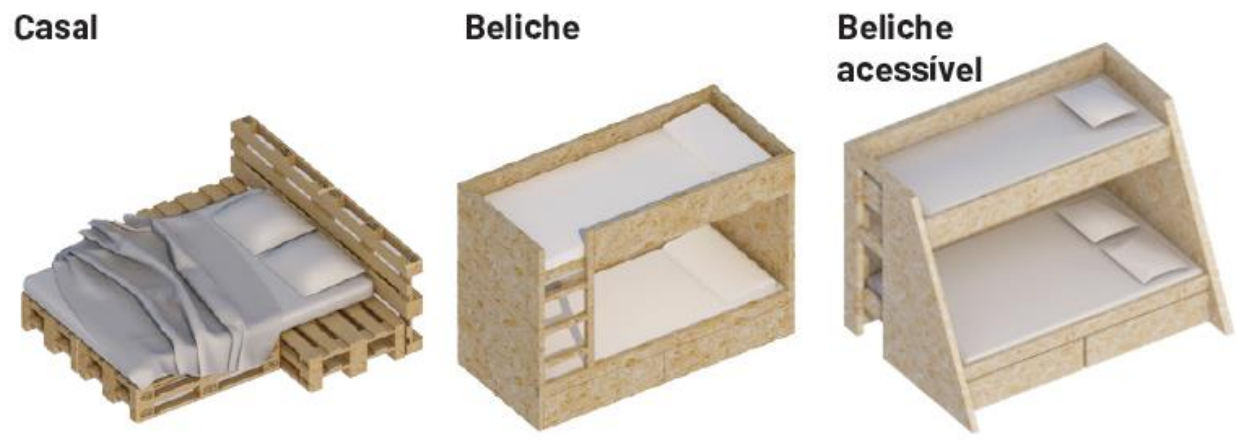

Fonte: Silva, 2019

Fig. 17: Vista externa área da piscina

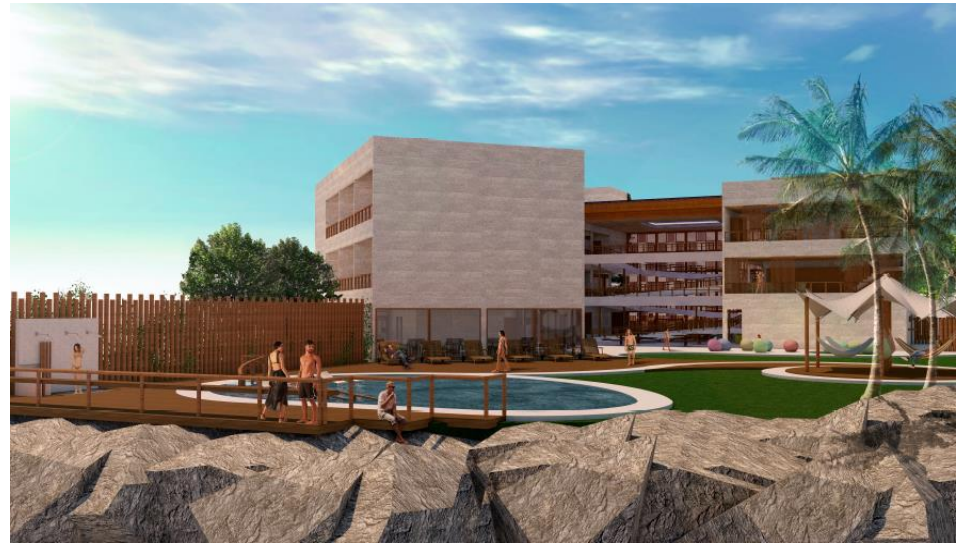

Fonte: Silva, 2019
Fig. 18: Corte/Vista interna recepção

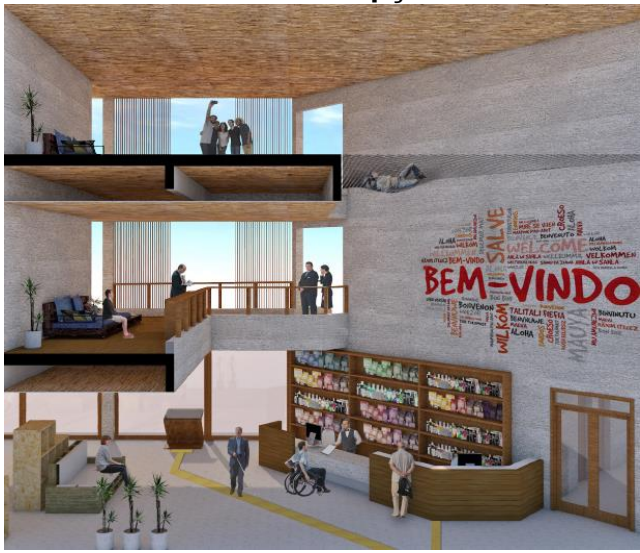

Fonte: Silva, 2019

\footnotetext{
${ }^{3}$ O OSB (Oriented Strand Board) é um painel estrutural de tiras de madeira orientadas perpendicularmente, em diversas camadas, o que aumenta sua resistência mecânica e rigidez. Essas tiras são unidas com resinas aplicadas sob altas temperatura e pressão. Através desse processo de engenharia automatizado, os painéis permanentemente controlados e testados para verificar seus níveis de acordo com os padrões de qualidade. É um painel ecologicamente correto. Texto extraído do orientador técnico da Masisa do Brasil LTDA. Disponível em: http://www.montagge.com.br/osb.htm

${ }^{4} \mathrm{O}$ pallet é construído de madeira, alumínio, aço, plástico, fibra, etc. Os mais comuns são os pallets de madeira. O pallet deve ser construído de forma resistente para que a carga unitizada seja manipulada e empilhada.
} 


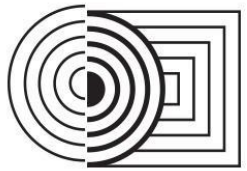

$17^{\circ}$ ERGODESIGN \& USIHC 2019

PUC-Rio, 11 a 13 de dezembro

Rio de Janeiro, RJ, Brasil $17^{\circ}$ Ergodesign - Congresso Internacional de Ergonomia e Usabilidade de Interfaces Humano Tecnológica: Produto, Informações Ambientes Construídos e Transporte

$17^{\circ}$ USIHC - Congresso Internacional de Ergonomia e Usabilidade de Interfaces Humano Computador

\section{CONSIDERAÇÕES FINAIS}

O desafio foi grande mas também bastante enriquecedor, aliado ainda a temática da tipologia hostel, ainda tão nova no nosso país. Na busca por referências, principalmente teóricas, sobre a temática de hospedagem, em especial, sobre hostels, o que se observa é que seu estudo no Brasil ainda está em um nível embrionário, começando a despertar a curiosidade de alguns, ainda não atingiu ao status de classificação dos meios de hospedagem na rede de turismo.

Trazer o projeto Jangada Hostel foi uma forma de discutir e se pensar nas questões de viés econômico e social, projetando com foco nas pessoas, inclusive as com deficiência e mobilidade reduzida, refletindo sobre como a arquitetura pode desempenhar seu papel e contribuir para tais questões através da criação de espaços.

Nas referências estudadas o que se observa é que a temática é muitas vezes deixada para um segundo momento, não estando nos planos desde o início, porém para a arquitetura ser acessível é realmente necessário tratar estes aspectos como premissa para a concepção de projeto e não tratar de adequações a posteriori.

\section{REFERÊNCIAS}

ASSOCIAÇÃO BRASILEIRA DE NORMAS TÉCNICAS. ABNT NBR 9050. Acessibilidade e edificações, mobiliário, espaços e equipamentos urbanos. Rio de Jjaneiro. 2015.

BRASIL. Ministério do Turismo. Turismo e Sustentabilidade. Orientações para prestadores de serviços turísticos. Brasília, 2016. Disponível em: www.turismo.gov.br

BRASIL.Ministério do Turismo. Marcos conceituais. Brasília, DF. 2006.

BRASIL.Ministério do Turismo. Estudo da Demanda Turística Internacional. Brasília, DF. 2016.

BRASIL.Ministério do Turismo. Plano Nacional de Turismo (PNT) 2018-2022 . brasília, DF. 2018.

Brasil. Ministério do Turismo. Secretaria Nacional de Políticas de Turismo. Turismo e acessibilidade: manual de orientações. 2. ed. - Brasília: Ministério do Turismo, 2006.

CARVALHO, A. S.; MOREIRA, C. B. G.; LIMA, T. P. A. A Acessibilidade dos Lugares: Reflexões e Práticas. In: VI SEMINÁRIO DA ASSOCIAÇÃO BRASILEIRA DE PESQUISA E PÓSGRADUAÇÃO EM TURISMO, 6., São Paulo, 2009.

HONORIO, I.C. Desenho Universal no Turismo: acessibilidade para pessoas com deficiência no segmento do turismo de eventos em Fortaleza, CE. Dissertação de Mestrado apresentada ao Curso de Mestrado Profissional em Gestão de Negócios Turísticos da Pró-Reitoria de PósGraduação e Pesquisa do Centro de Ciências e Tecnologia e Centro de Estudos Sociais Aplicados da Universidade Estadual do Ceará, 2014.

MENDES, Bruna C.; PAULA, Nilma Morcef de. A Hospitalidade, o Turismo e a Inclusão Social para Cadeirantes. Revista Turismo em Análise, v. 19, n. 2, ago. 2008, p. 329-343.

SASSAKI, Romeu Kazume. Inclusão no lazer e turismo: em busca da qualidade de vida. São Paulo: Áurea, 2003.

DANDES, Marisa. Informações sobre filiação. [mensagem pessoal] recebida por <steephaniesilva@gmail.com> em 23-04-2018. 
SILVA, Stephanie Ciqueira. Jangada Hostel: uma proposta de hospitalidade aberta. Trabalho de Conclusão de Curso. Departamento de Arquitetura, Urbanismo e Design. Universidade Federal do Ceará. .2019. 132f. il. color.

VARGAS, Heliana Comin; PAIVA, Ricardo Alexandre (Org). Turismo, Arquitetura e Cidade. Barueri, SP: Manole, 2016.

\section{Sites}

HOSTELLING INTERNATIONAL. Perguntas frequentes. Disponível em $<$ https://www.hihostel.com/pt//pages/469> Acesso em: 2019-06-21. 